ECCOMAS

Proceedia
COMPDYN 2021

$8^{\text {th }}$ ECCOMAS Thematic Conference on Computational Methods in Structural Dynamics and Earthquake Engineering M. Papadrakakis, M. Fragiadakis (eds.) Streamed from Athens, Greece, 28 - 30 June 2021

\title{
GEOMETRICALLY NONLINEAR FORCED TRANSVERSE VIBRATIONS ANALYSIS OF TAPERED EULER-BERNOULLI BEAMS
}

\author{
I. El Hantati ${ }^{1,2}$, A. Adri ${ }^{1}$, H. Fakhreddine ${ }^{1,2}$, S. Rifai ${ }^{1}$, R. Benamar ${ }^{3}$ \\ ${ }^{1}$ Laboratory of Production Mechanics and Industrial Engineering (LMPGI), Higher School of Technology, Has- \\ san II University of Casablanca, Km 7, Route El Jadida, B.P. 8012 Oasis, Casablanca, Morocco \\ hantati.issam@gmail.com, ahmedadri@gmail.com, hatim.fakhreddine@gmail.com, said57.rifai@gmail.com \\ ${ }^{2}$ Doctoral Studies Centre of National High School of Electricity and Mechanics (ENSEM) \\ Route d'El Jadida, Km 7, Oasis, Casablanca 8018, Morocco \\ hantati.issam@gmail.com, hatim.fakhreddine@gmail.com \\ ${ }^{2}$ Mohammed V University in Rabat, EMI-Rabat, LERSIM, Agdal, \\ B.P. 765, Rabat, Morocco \\ rhali.benamar@gmail.com
}

\begin{abstract}
Tapered beams like structures are widely used in many fields including mechanical and civil engineering, such as high-rise buildings, robot arms, etc. The objective of this paper is to study the geometrically nonlinear free and forced transverse vibrations of tapered beams with a constant width and a linearly varying depth. The theoretical model is based on the EulerBernoulli beam theory and the Von Kármán assumptions for geometrical nonlinearity. The motion is assumed to be harmonic and the transverse displacement function of the nonlinear beam is expanded as a series of linear modes, determined by solving the linear problem in terms of Bessel functions satisfying the boundary conditions. The discretized expressions for total beam strain and kinetic energies are derived, and by application of Hamilton's principle, the problem is reduced to a non-linear algebraic system solved using a previously developed approximate method (the so-called second formulation). The effect of the linear variation of depth on the non-linear behaviour of the beam is examined and then illustrated. Using the single-mode approach, the non-linear dynamic behaviour of the tapered beam is studied in the forced case. The effects of the excitation level of the applied harmonic force are investigated and illustrated for various scenarios.
\end{abstract}

Keywords: tapered beam, transverse vibrations, nonlinear vibrations, forced vibrations 


\section{INTRODUCTION}

In civil engineering, aeronautics or mechanical engineering, the beams used are commonly non-uniform. This type of beams are often subjected to free or forced vibrations, especially in some applications such as aircraft wings or steel structures. Many works have been devoted to the dynamic behaviour of tapered beams under different boundary conditions and both the Euler-Bernoulli and Timoshenko beam's theory have been used.

The literature review may go back to [1], in which Sanger exposed a general solution in terms of Bessel function of order $n$ for a range of beams, for different classical boundary conditions as a fixed end, a simply supported end, etc. Goel studied in [2] the transverse vibrations of tapered beams with elastically restrained ends, as well as the effect of a concentrated mass at the free end of a cantilever tapered beam. Craver et al. [3] examined the free vibrations of Euler Bernoulli tapered cantilever beams, elastically restrained at an arbitrary position over its length, using the straight search and bisection method. Abrate [4] gave simple formulas for predicting the fundamental frequencies using one term Rayleigh-Ritz approximations. De Rosa and Auciello [5] investigated a tapered beam of linearly varying width and depth and with rotational and translational springs at both ends using the false position method. In order to solve the natural frequencies of the free vibration of beams with variable flexural rigidity and mass density, Yong Huang and Xian-Fang Li presented in [6] a new approach based on Fredholm's integral equations. S.M. Abdelghany et al. [7] investigated the case of nonuniform circular Euler-Bernoulli beam vibrations using the differential transformation method. Fatemeh Sohani and H. R. Eipakchi [8] studied the flexural vibrations of Euler Bernoulli and Timoshenko beams with an arbitrary varying cross-section using on the perturbation technique.

Despite the large literature devoted to the dynamic behaviour of tapered beams, only few authors have considered the effect of geometrical non-linearity. This effect was studied by L. S. Raju et al. in [9], for a tapered beam of rectangular cross-section with two types of linear taper, one corresponding to the width and the other to the depth. The study was based on Galerkin's method. The analysis of the non-linear behaviour of Timoshenko tapered beams with linear variation in width and depth has been carried out by Minmao Liao and Hongzhi Zhong [10], based on the differential quadrature method. Kumar et al. [11] investigated large amplitudes of free vibrations of axially functionally graded tapered beams under different boundary conditions, taper profiles and material properties. The principle of minimum total potential energy was applied in the static case while Hamilton's principle was used in the dynamic analysis.

The present work is focused on the study of geometrically non-linear free and forced vibrations of tapered beams and constitutes a continuation of the work previously initiated by Benamar et al. [12]-[22] in the perspective of a contribution to a non-linear modal analysis theory of free and forced vibrations of structures. The purpose of this paper is to study the geometrically nonlinear free and forced transverse vibrations of tapered beams with a constant width and a linearly varying depth. The theoretical model is based on Euler-Bernoulli's beam theory and the Von Kármán geometrical nonlinearity assumptions. The motion is assumed to be harmonic and the transverse displacement function of the nonlinear beam is expanded as a series of the linear modes, determined by solving the linear problem in terms of Bessel functions and the boundary conditions. The discretized expressions for total beam strain and kinetic energies are derived, and by applying Hamilton's principle, the problem is reduced to a non-linear algebraic system solved using an approximate method (the so-called second formulation). The effect of the linear variation of depth on the non-linear behaviour of the beam is 
examined and then illustrated. Using the single-mode approach, the non-linear dynamic behaviour of the tapered beam is studied in the forced case. The effects of the excitation level of the applied harmonic force are investigated and illustrated for various scenarios.

\section{GENERAL FORMULATION}

\subsection{Linear formulation}

This study concerns a non-uniform fully-clamped tapered Euler-Bernoulli beam subjected to transverse vibrations. A thin rectangular cross-section tapered beam of a constant width and a linearly varying depth, denoted by beam (a) is considered.
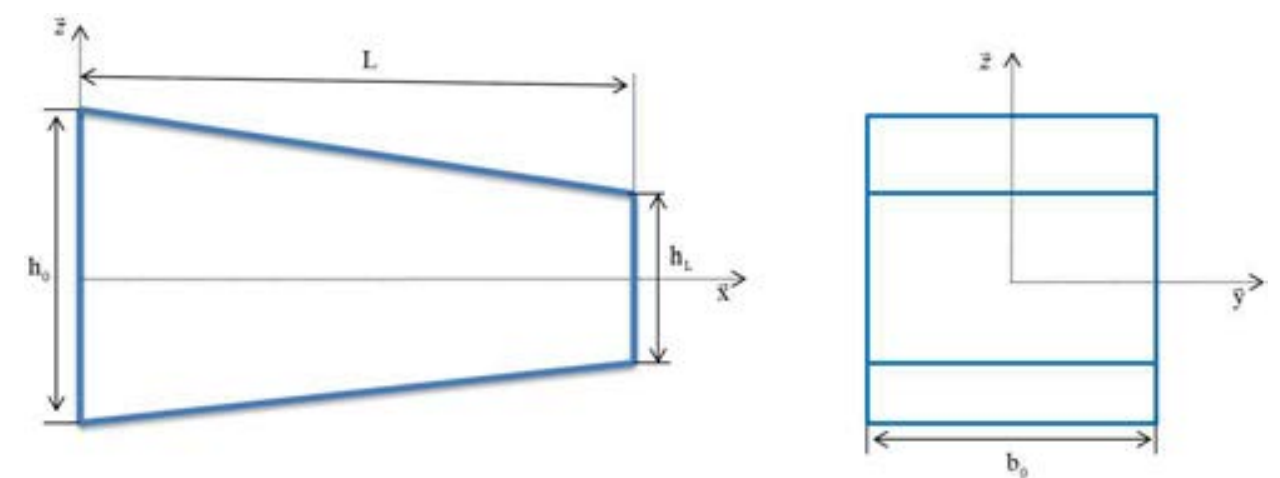

Figure 1: Coordinates system for the tapered beam studied.

Setting that $\mathrm{h}_{(\mathrm{x})}=\mathrm{h}_{0}\left(1-\alpha\left(\frac{\mathrm{x}}{\mathrm{L}}\right)\right)$, where $\mathrm{h}_{(\mathrm{x})}$ and $\alpha$ present the depth of the beam and the taper ratio equal to $1-\mathrm{h}_{\mathrm{L}} / \mathrm{h}_{0}$. The area and inertia functions are given as follows:

$$
\begin{aligned}
& \mathrm{S}(\mathrm{x})=\mathrm{h}_{(\mathrm{x})} \times \mathrm{b}_{0} \\
& \mathrm{I}(\mathrm{x})=\frac{\mathrm{h}_{(\mathrm{x})}^{3} \times \mathrm{b}_{0}}{12}
\end{aligned}
$$

The equation of motion of the tapered beam in the case of free transverse vibrations can be expressed as in [23]:

$$
\frac{\partial^{2}}{\partial \mathrm{x}^{2}}\left\{\mathrm{EI}_{(\mathrm{X})} \frac{\partial^{2} w_{i}}{\partial \mathrm{x}^{2}}\right\}+\rho \mathrm{S}_{(\mathrm{X})} \frac{\partial^{2} w_{i}}{\partial t^{2}}=0 ; x \epsilon[0 L] \quad(\text { For } i=1,2 \ldots, 10)
$$

Where E, $\rho$ and $t$ are respectively the Young's modulus, the density of the beam material and time. $w$ presents the transverse displacement function of $\mathrm{x}$ and $\mathrm{t}$, supposed to be separated into two functions $w(\mathrm{x}, \mathrm{t})=\mathrm{W}(\mathrm{x}) \times \varphi(\mathrm{t})$. By substituting $\xi=1-\alpha\left(\frac{\mathrm{x}}{\mathrm{L}}\right)$ in the equation of motion (6), leads to the formulation previously stated in [23]:

$$
\xi^{2} \frac{\mathrm{d}^{4} \mathrm{~W}_{i}}{\mathrm{~d} \xi^{4}}+2(\mathrm{n}+2) \xi \frac{\mathrm{d}^{3} \mathrm{~W}_{i}}{\mathrm{~d} \xi^{3}}+(\mathrm{n}+2)(\mathrm{n}+1) \frac{\mathrm{d}^{2} \mathrm{~W}_{i}}{\mathrm{~d} \xi^{2}}-\frac{\beta_{i}^{4}}{\alpha} \mathrm{W}_{i}=0
$$

Where:

$$
\beta_{\mathrm{i}}=\sqrt[4]{\frac{\rho \mathrm{S}_{0} \omega_{\mathrm{i}}^{2} \mathrm{~L}^{4}}{\mathrm{EI}_{0}}} \text { and } \mathrm{n}=1
$$


The eigenvalue parameter is denoted by $\beta_{\mathrm{i}}$. The solution of Eq. (4) presents the linear modes form given in [23] as follows:

$$
W_{i}(\phi)=\frac{1}{\phi}\left(A_{i} J_{l}(\phi)+B_{i} Y_{1}(\phi)+C_{i} I_{l}(\phi)+D_{i} K_{l}(\phi)\right)
$$

Where $\phi=(2 \beta \sqrt{\xi}) \alpha^{-1}$

In equation (6) $\mathrm{A}_{1}, \mathrm{~B}_{1}, \mathrm{C}_{1}$ and $D_{1}$ present constants that can be determined from the boundary conditions, $\mathrm{J}_{1}$ and $\mathrm{Y}_{1}$ are Bessel functions of the first and second kinds in order $1, \mathrm{I}_{1}$ and $\mathrm{K}_{1}$ are the modified Bessel functions of first and second kinds in order 1.

After setting $\mathrm{x}^{*}=\mathrm{x} / \mathrm{L}$ for $x^{*} \epsilon\left[\begin{array}{ll}0 & 1]\end{array}\right.$, the beam end conditions are given by:

The end conditions at the left side:

$$
\left.\mathrm{W}_{\mathrm{i}}\right|_{\mathrm{x}^{*}=0}=\left.\frac{\mathrm{d} \mathrm{W}_{\mathrm{i}}}{\mathrm{dx}^{*}}\right|_{\mathrm{x}^{*}=0}=0
$$

The end conditions at the right side:

$$
\left.\mathrm{W}_{\mathrm{i}}\right|_{\mathrm{x}^{*}=1}=\left.\frac{\mathrm{dW}_{\mathrm{i}}}{\mathrm{dx}^{*}}\right|_{\mathrm{x}^{*}=1}=0
$$

The substitution of equation (6) into equations (11 and 12) leads to four equations, expressed in the following forms:

$$
\begin{aligned}
& \mathrm{A}_{\mathrm{i}} \mathrm{J}_{1}\left(\varphi_{0}\right)+\mathrm{B}_{\mathrm{i}} \mathrm{Y}_{1}\left(\varphi_{0}\right)+\mathrm{C}_{\mathrm{i}} \mathrm{I}_{1}\left(\varphi_{0}\right)+\mathrm{D}_{\mathrm{i}} \mathrm{K}_{1}\left(\varphi_{0}\right)=0 \\
& \mathrm{~A}_{\mathrm{i}} \mathrm{J}_{2}\left(\varphi_{0}\right)+\mathrm{B}_{\mathrm{i}} \mathrm{Y}_{2}\left(\varphi_{0}\right)-\mathrm{C}_{\mathrm{i}} \mathrm{I}_{2}\left(\varphi_{0}\right)+\mathrm{D}_{\mathrm{i}} \mathrm{K}_{2}\left(\varphi_{0}\right)=0 \\
& \mathrm{~A}_{\mathrm{i}} \mathrm{J}_{1}\left(\varphi_{\mathrm{L}}\right)+\mathrm{B}_{\mathrm{i}} \mathrm{Y}_{1}\left(\varphi_{\mathrm{L}}\right)+\mathrm{C}_{\mathrm{i}} \mathrm{I}_{1}\left(\varphi_{\mathrm{L}}\right)+\mathrm{D}_{\mathrm{i}} \mathrm{K}_{1}\left(\varphi_{\mathrm{L}}\right)=0 \\
& \mathrm{~A}_{\mathrm{i}} \mathrm{J}_{2}\left(\varphi_{\mathrm{L}}\right)+\mathrm{B}_{\mathrm{i}} \mathrm{Y}_{2}\left(\varphi_{\mathrm{L}}\right)-\mathrm{C}_{\mathrm{i}} \mathrm{I}_{2}\left(\varphi_{\mathrm{L}}\right)+\mathrm{D}_{\mathrm{i}} \mathrm{K}_{2}\left(\varphi_{\mathrm{L}}\right)=0
\end{aligned}
$$

Where $\varphi_{0}=\frac{2 \beta_{\mathrm{i}}}{\alpha}$ and $\varphi_{\mathrm{L}}=\frac{2 \beta_{\mathrm{i}}}{\alpha} \sqrt{1-\alpha}$.

The satisfaction of equations (13-16) leads to an homogeneous system which can be expressed by the following matrix form:

$$
\left[\begin{array}{cccc}
J_{1}\left(\varphi_{0}\right) & \mathrm{Y}_{1}\left(\varphi_{0}\right) & \mathrm{I}_{1}\left(\varphi_{0}\right) & \mathrm{K}_{1}\left(\varphi_{0}\right) \\
\mathrm{J}_{2}\left(\varphi_{0}\right) & \mathrm{Y}_{2}\left(\varphi_{0}\right) & -\mathrm{I}_{2}\left(\varphi_{0}\right) & \mathrm{K}_{2}\left(\varphi_{0}\right) \\
\mathrm{J}_{1}\left(\varphi_{\mathrm{L}}\right) & \mathrm{Y}_{1}\left(\varphi_{\mathrm{L}}\right) & \mathrm{I}_{1}\left(\varphi_{\mathrm{L}}\right) & \mathrm{K}_{1}\left(\varphi_{\mathrm{L}}\right) \\
\mathrm{J}_{2}\left(\varphi_{\mathrm{L}}\right) & \mathrm{Y}_{2}\left(\varphi_{\mathrm{L}}\right) & -\mathrm{I}_{2}\left(\varphi_{\mathrm{L}}\right) & \mathrm{K}_{2}\left(\varphi_{\mathrm{L}}\right)
\end{array}\right] \times\left\{\begin{array}{l}
\mathrm{A}_{\mathrm{i}} \\
\mathrm{B}_{\mathrm{i}} \\
\mathrm{C}_{1} \\
\mathrm{D}_{1}
\end{array}\right\}=\left\{\begin{array}{l}
0 \\
0 \\
0 \\
0
\end{array}\right\}
$$

The non-trivial solutions corresponding to the natural frequencies are derived from equation (17), solved iteratively by the Newton-Raphson method. Then the constants $A_{1}, B_{1}, C_{1}$ and $D_{1}$ are determined by the usual classical algebra procedure. 


\subsection{Non-linear formulation}

\subsubsection{Free vibration}

The kinetic energy $T$ of the tapered beam can be presented in the following form:

$$
T=\frac{\rho}{2} \int_{0}^{L} S(x)\left(\frac{\delta w}{\delta t}\right)^{2} d x
$$

The total strain energy $\mathrm{V}$ is the sum of the strain energy due to bending and the axial strain energy due to the non-linear stretching forces induced by the large deflections, respectively denoted by $\mathrm{V}_{\mathrm{f}}$ and $\mathrm{V}_{\mathrm{a}}$ and written as follows:

$$
\begin{gathered}
\mathrm{V}=\mathrm{V}_{\mathrm{f}}+\mathrm{V}_{\mathrm{a}} \\
\mathrm{V}_{\mathrm{f}}=\frac{1}{2} \int_{0}^{L} E I(x)\left(\frac{d^{2} w_{i}}{d x^{2}}\right)\left(\frac{d^{2} w_{j}}{d x^{2}}\right) d x \\
V_{a}=\frac{1}{2} \frac{N_{x}^{2}}{E} \int_{0}^{L} \frac{d x}{S(x)}
\end{gathered}
$$

Where $N_{x}$ presents the non-linear axial stretching forces in the beam, which may be written in the form reported in [9]:

$$
N_{x}=\frac{E}{2} \cdot \frac{\int_{0}^{L}\left(\frac{d w_{i}}{d x}\right)^{2} d x}{\int_{0}^{L} \frac{d x}{S}}
$$

The dynamic behaviour of the system is studied by applying Hamilton's principle, stated formally as:

$$
\delta \int_{0}^{\frac{2 \omega}{t}}(\mathrm{~V}-\mathrm{T}) \mathrm{dt}=0
$$

Assuming a harmonic motion, the transverse displacement can be written as:

$$
w(x, t)=a_{i} W_{i}(x) \sin (\omega t) \quad(\text { For } i=1,2 \ldots, \mathrm{n})
$$

In which $W_{i}(x), a_{i}$ and $\omega$ present the linear mode, the basic function contribution coefficients and the associated frequency.

After Substituting equation (24) in the expressions for the kinetic energy, the axial deformation energy due to non-linear stretching forces and the deformation energy due to the bending, one gets:

$$
\begin{aligned}
& T=\frac{1}{2} \omega^{2} a_{i} a_{i}(\cos (\omega t))^{2} m_{i j} \\
& V_{a}=\frac{1}{2} a_{i} a_{j} a_{k} a_{l}(\sin (\omega t))^{4} b_{i j k l} \\
& V_{f}=\frac{1}{2} a_{i} a_{i}(\sin (\omega t))^{2} k_{i j}
\end{aligned}
$$

Where $k_{i j}, b_{i j k l}$ and $m_{i j}$ denote the matrix of the stiffness due to $\mathrm{V}_{\mathrm{f}}$, the non-linearity tensor due to $V_{a}$ and the mass matrix attributable to $T$. Equation (23) is extended by adding equations $(25,26$ and 27) into it, which can be expressed in the following form:

$$
2 a_{i} k_{i r}+3 a_{i} a_{j} a_{k} b_{i j k r}-2 \omega^{2} a_{i} m_{i r}=0 \quad ; \quad \mathrm{r}=1, \ldots, \mathrm{n}
$$


Equation (28) can be expressed in a matrix form as follows:

$$
2[K]\{A\}+3[B(\{A\})]\{A\}-2 \omega^{2}[M]\{A\}=0
$$

In which $\left(k_{i r}\right),\left(m_{i r}\right),\left(a_{j} a_{k} b_{i j k l}\right)$ and $\left(a_{i}\right)$ are converted into $[K],[M],[B(\{A\})]$ and $\{A\}$. Setting some dimensionless parameters as below:

$$
\begin{gathered}
\frac{W_{i}\left(x^{*}\right)}{W_{i}^{*}\left(x^{*}\right)}=h_{0} ; \frac{\omega^{2}}{\omega^{* 2}}=\frac{E I_{1}}{\rho S_{1} L^{4}} ; \frac{M_{i j}}{M_{i j}{ }^{*}}=\rho S_{1} h_{0}{ }^{2} \\
k_{i j}=\frac{E I_{1} h_{0}{ }^{2}}{L^{3}} k_{i j}{ }^{*} ; b_{i j k l}=\frac{E I_{1} h_{0}{ }^{2}}{L^{3}} b_{i j k l}{ }^{*}
\end{gathered}
$$

After substituting the dimensionless parameters in equation (29), this later becomes:

$$
\left[K^{*}\right]\{A\}+\frac{3}{2}\left[B^{*}(\{A\})\right]\{A\}-\omega^{* 2}\left[M^{*}\right]\{A\}=0
$$

In order to determine the frequency $(\omega)$ and the column vector of the contribution coefficients $\{\mathrm{A}\}$, which represent the unknowns of equation (35), the so-called second formulation had been used. This method was previously developed by EL KADIRI et al. in [16].

\subsubsection{Forced vibrations}

To study the non-linear forced vibrations, the tapered beam is supposed to be excited by a concentrated harmonic force. The dynamic behaviour of this beam is then studied using Hamilton's principle including the forcing term, and can be expressed as in ref[18]:

$$
\delta \int_{0}^{\frac{2 \omega}{t}}(V-T+F) d t=0
$$

The concentrated harmonic force applied at the point $\mathrm{x}_{0}$ can be written as in[14]:

$$
\mathrm{F}_{i}^{c}=F^{c} \cos (\omega t) w_{i}\left(x_{0}\right)=\mathrm{f}_{i}^{c} \cos (\omega t)
$$

Where the dimensionless force $\mathrm{f}_{i}^{c^{*}}$ can be written as:

$$
\mathrm{f}_{i}^{c^{*}}=\frac{L^{3}}{E I_{1}} F^{c} w_{i}^{*}\left(x_{0}\right)
$$

The mathematical development of equation (36) obtained after substitution of equations $(25,26,27$ and 37$)$, as well as the dimensionless parameters can be given as follows:

$$
\left[K^{*}\right]\{A\}+\frac{3}{2}\left[B^{*}(\{A\})\right]\{A\}-\omega^{* 2}\left[M^{*}\right]\{A\}=\left\{F^{c^{*}}\right\}
$$

Equation (32) was solved using the single mode approach, previously applied by AZRAR et al [14]. This approach consists of using only the predominant mode. The predominant mode and the contribution coefficients are denoted by " $i$ " and " $\mathrm{a}_{i}$ ", leading to the following equation:

$$
1+3 \mathrm{a}_{i}{ }_{i} \frac{\mathrm{B}_{i i i i}{ }^{*}}{\mathrm{~K}_{i i}{ }^{*}}-\frac{\mathrm{f}_{i}^{\mathrm{c}^{*}}}{\mathrm{a}_{i} \mathrm{~K}_{i i}{ }^{*}}=\left(\frac{\omega_{\mathrm{nl}}^{*}}{\omega_{1}^{*}}\right)^{2}
$$

Where $\omega_{1}^{*}=\frac{\mathrm{K}_{\mathrm{ii}}{ }^{*}}{\mathrm{M}_{\mathrm{ii}}{ }^{*}}$. 


\section{NUMERICAL RESULTS AND DISCUSSION}

\subsection{Free vibration}

The beam investigated in this study is a tapered beam of a constant width, A linearly varying depth and IS characterised by a taper ratio equal to $\alpha=0.8$. The first four eigenvalues of this tapered beam are compared to those of [23] for two end conditions: a tapered beam clamped at the both sides denoted by $\mathrm{C}-\mathrm{C}$, and a tapered beam simply-supported at the both sides denoted by S-S. The results of this comparison are summarised in table 1.

Table 1: The first four eigenvalues of tapered beams for different end conditions. The taper ratio

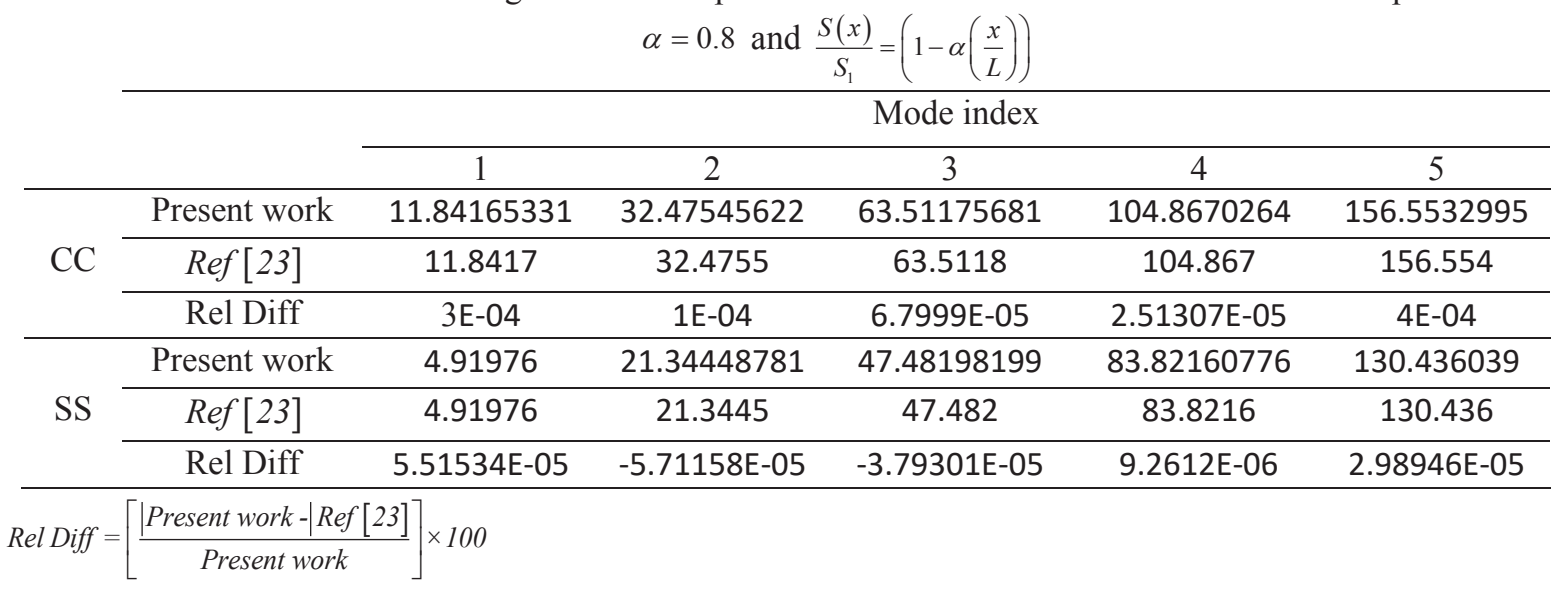

The comparisons made in Table (1) show an excellent agreement, with a relative difference not exceeding $0,0004 \%$ for the whole range of frequencies considered.

In the nonlinear free vibration case, the tapered beam investigated remains characterised by the same taper ratio and clamped at the both ends. Figure (2) shows the amplitude dependence of the non-linear frequency parameter on the maximum vibration amplitude.

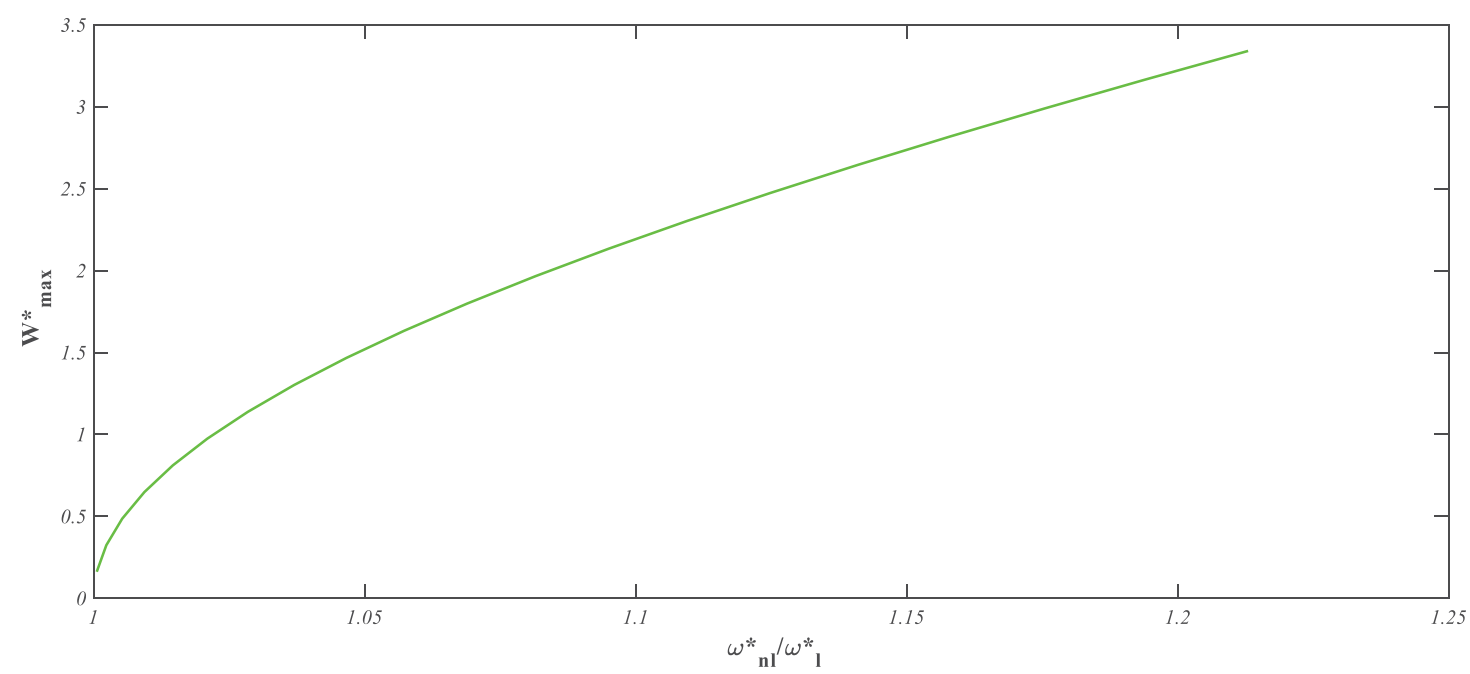

Figure (2) Backbone curve of the tapered beams studied, corresponding to the first nonlinear mode. 


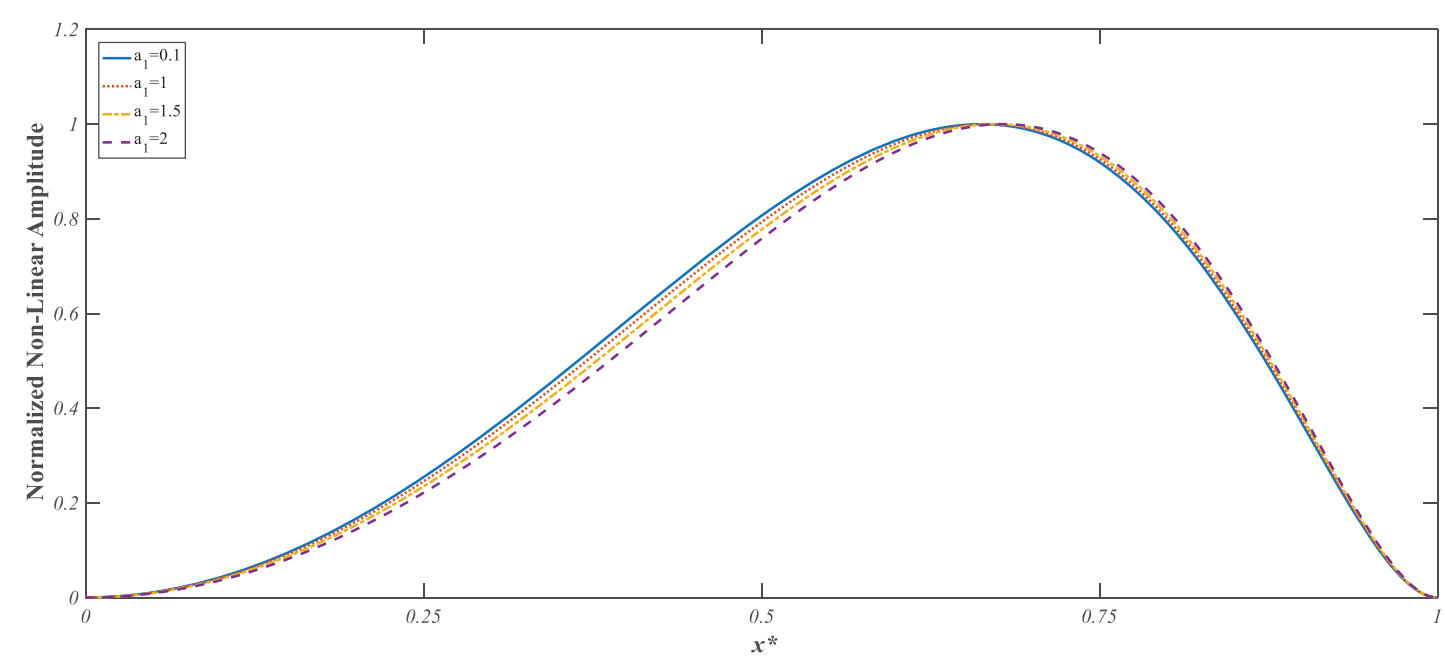

Figure (3): The normalized first non-linear mode of the tapered beam for different amplitude values

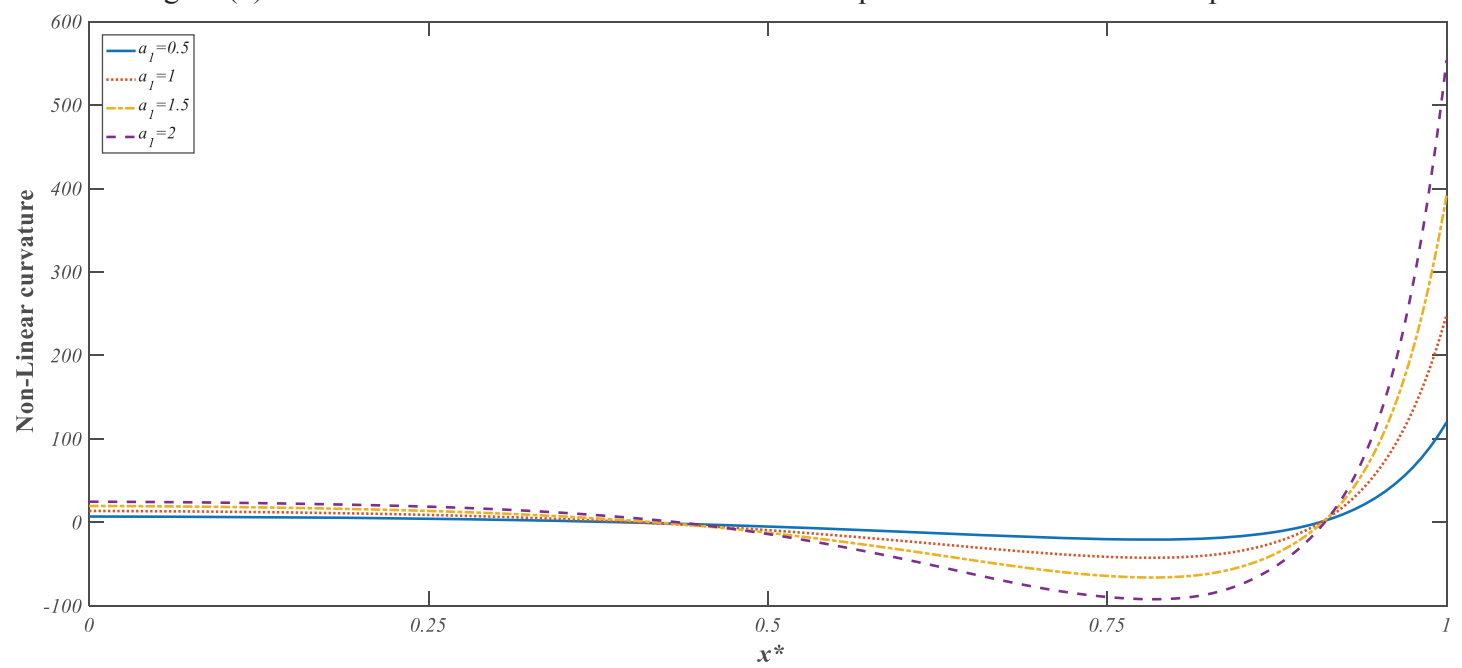

Figure (4): The Non-linear curvature distribution associated to the normalized first non-linear mode for different amplitude values

It may be seen in the backbone curve given in Figure (2) that increasing the maximum nondimensional amplitude $\mathrm{W}^{*}{ }_{\max }$ results in an increase the non-linear to linear frequency ratio, which is characteristic of a non-linearity of the hardening type. In addition, the bending moment distribution associated to the non-linear mode shows that the assumption of neglecting the geometrical non-linearity may be misleading. For instance, the non-linear bending moment of the tapered beam at the right end with a contribution coefficient a $1=1$ is 248.84 , while the linear bending moment predicted by linear theory is 237.21 , which corresponds to a percentage correction of $4,9 \%$. For a $1=1.5$, the non-linear bending moment equals 392.41 , while the linear bending moment is 355.81, resulting in a percentage difference of $10,28 \%$. For a contribution coefficient $\mathrm{a} 1=2$, the non-linear and linear bending moments are equal respectively to 553.71 and 474.42 , which corresponds to percentage correction of $16,71 \%$. .

\subsection{Forced vibration}

The fully-clamped tapered Euler-Bernoulli beam is excited by a concentred force located at the middle. The generalised forces calculated in Table (2) shows that the first mode remains predominant, which justifies use of the approximate theory developed in [16] for the determination of the non-linear frequency response curve in the neighbourhood of the first mode (NLFRF). The following Table illustrates the type of results obtained. 
Table 2: Percentage of generalized forces exciting the first five symmetric modes of tapered beams excited by a concentred force located at the middle of it.

\begin{tabular}{cccccc} 
& \multicolumn{6}{c}{ Modes } \\
\cline { 2 - 6 } & 1 & 3 & 5 & 7 & 9 \\
\hline$\left|F^{c} w_{i}^{*}\left(x_{f}\right)\right|$ & 18,41 & 9,20 & 0,35 & 9,98 & 16,32 \\
\hline
\end{tabular}

Using the single-mode approach, an investigation of the dynamic behaviour of the tapered beam was carried out in the vicinity of the predominant mode. The response curves were plotted for the tapered beams shown in Figure (1), which was excited by a concentric harmonic force. Five scenarios was investigated in which the excitation level varied in the following way $\left[\mathrm{F}^{\mathrm{c}}=10^{\mathrm{n}}\right]($ for $\mathrm{n}=0,1,2$ and 3$)$.

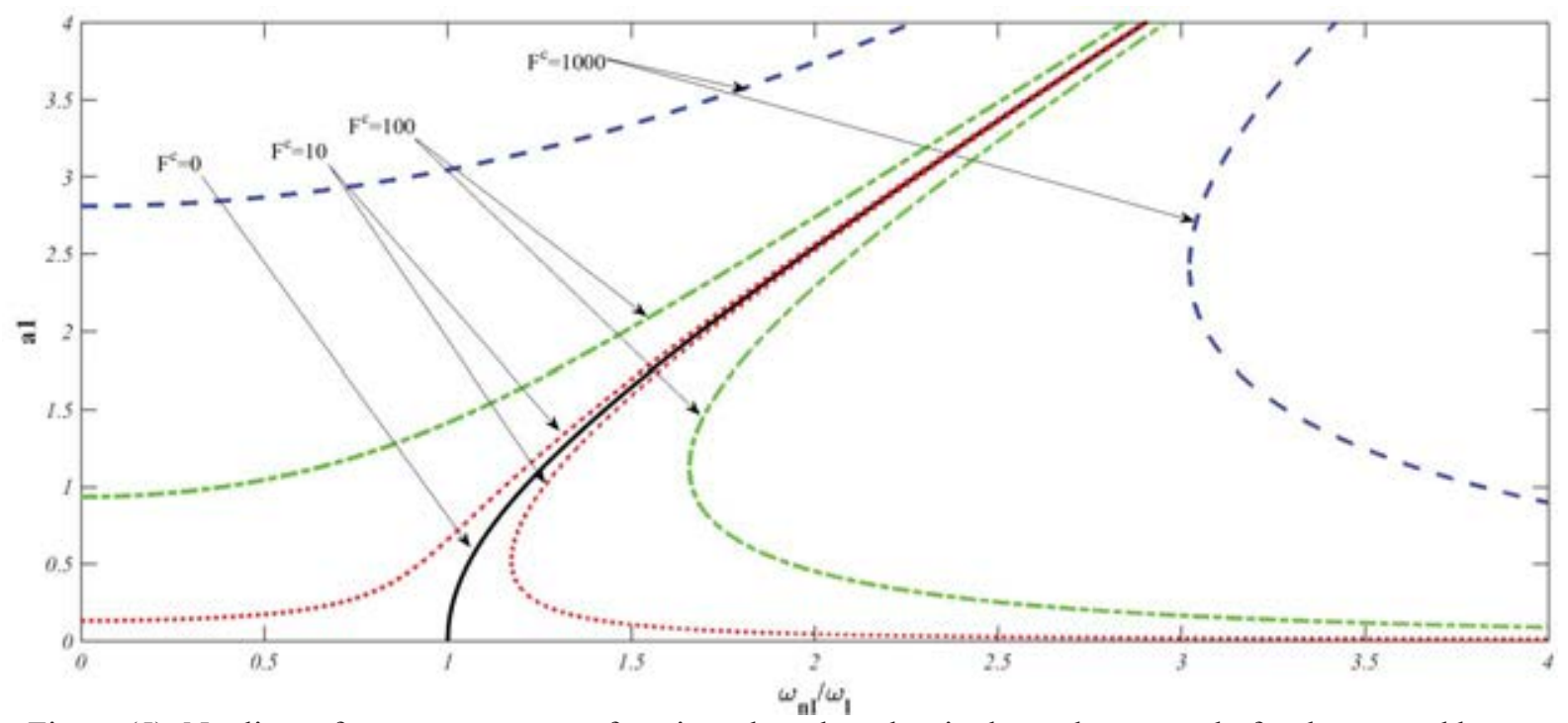

Figure (5): Nonlinear frequency response functions, based on the single mode approach, for the tapered beam subjected to four levels of excitation.

Figure (5) shows the effect of the geometrical non-linearity in the case of forced vibrations, with the jump phenomenon region commonly found in non-linear vibrations. The hardening behaviour is also visible, as well as the non-proportional progression in the frequency response with the excitation intensity.

\section{CONCLUSION}

Geometrically non-linear transverse vibrations of tapered beams were studied analytically using the Euler-Bernoulli beam theory and Von Karman nonlinearity assumptions. The solution of the linear problem was obtained for a tapered beam of a constant width, a linearly variable depth and a taper ratio equal to 0.8 . The linear modes obtained were used as basic functions in the analysis of non-linear vibrations. To solve the non-linear algebraic system derived via application of Hamilton's principle, a previously developed approximate method, called the second formulation, was applied. A comparison was made between the result obtained from the numerical method used here and those obtained using the transfer matrix method. This comparison shows an excellent agreement since the relative difference does not exceed $0.0002 \%$. Then, the non-linear dynamic behaviour of tapered beams subjected to free vibrations was examined and illustrated by the backbone curve, nonlinear modes and curva- 


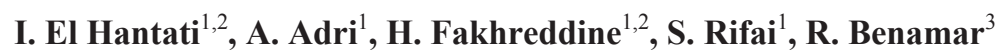

ture distributions, in which the hardening behaviour can be clearly observed. Using the singlemode approach, a study of the dynamic behaviour of the tapered beams in the forced case was carried out in the vicinity of the predominant mode. The effect of the force level was examined and illustrated for four excitation levels. The results illustrate the effect of geometrical non-linearity with the hardening type behaviour and the instable regions in which the jump phenomena can occur.

\section{REFRENCES}

[1] D. J. Sanger, "Transverse Vibration of a Class of Non-Uniform Beams," J. Mech. Eng. Sci., vol. 10, no. 2, pp. 111-120, 1968, doi: 10.1243/jmes_jour_1968_010_018_02.

[2] R. P. Goel, "Transverse vibrations of tapered beams," J. Sound Vib., vol. 47, no. 1, pp. 1-7, 1976, doi: 10.1016/0022-460X(76)90403-X.

[3] W. L. Craver and P. Jampala, "Transverse Vibrations of a Linearly Tapered Cantilever Beam With Constraining Springs," J. Sound Vib., vol. 166, no. 3, pp. 521-529, Sep. 1993, doi: 10.1006/jsvi.1993.1310.

[4] S. Abrate, "Vibration of non-uniform rods and beams," J. Sound Vib., vol. 185, no. 4, pp. 703-716, Aug. 1995, doi: 10.1006/jsvi.1995.0410.

[5] M. A. De Rosa and N. M. Auciello, "Free vibrations of tapered beams with flexible ends," Comput. Struct., vol. 60, no. 2, pp. 197-202, 1996, doi: 10.1016/00457949(95)00397-5.

[6] Y. Huang and X.-F. Li, "A new approach for free vibration of axially functionally graded beams with non-uniform cross-section," J. Sound Vib., vol. 329, no. 11, pp. 2291-2303, May 2010, doi: 10.1016/j.jsv.2009.12.029.

[7] S. M. Abdelghany, K. M. Ewis, A. A. Mahmoud, and M. M. Nassar, "Vibration of a circular beam with variable cross sections using differential transformation method," Beni-Suef Univ. J. Basic Appl. Sci., vol. 4, no. 3, pp. 185-191, Sep. 2015, doi: 10.1016/j.bjbas.2015.05.006.

[8] F. Sohani and H. R. Eipakchi, "Analytical solution for modal analysis of EulerBernoulli and Timoshenko beam with an arbitrary varying cross-section," Math. Model. Eng., vol. 4, no. 3, pp. 164-174, 2018, doi: 10.21595/mme.2018.20116.

[9] L. S. Raju, G. V. Rao, and K. K. Raju, "Large amplitude free vibrations of tapered beams," AIAA J., vol. 14, no. 2, pp. 280-282, 1976, doi: 10.2514/3.7095.

[10] M. Liao and H. Zhong, "Nonlinear vibration analysis of tapered Timoshenko beams," Chaos, Solitons \& Fractals, vol. 36, no. 5, pp. 1267-1272, Jun. 2008, doi: 10.1016/j.chaos.2006.07.055.

[11] S. Kumar, A. Mitra, and H. Roy, "Geometrically nonlinear free vibration analysis of axially functionally graded taper beams," Eng. Sci. Technol. an Int. J., vol. 18, no. 4, pp. 579-593, 2015, doi: 10.1016/j.jestch.2015.04.003.

[12] R. Benamar, M. M. K. Bennouna, and R. G. White, "The effects of large vibration amplitudes on the mode shapes and natural frequencies of thin elastic structures part I: Simply supported and clamped-clamped beams," J. Sound Vib., vol. 149, no. 2, pp. 179-195, Sep. 1991, doi: 10.1016/0022-460X(91)90630-3.

[13] R. Benamar, M. M. K. Bennouna, and R. G. White, "The Effects of Large Vibration Amplitudes on the Mode Shapes and Natural Frequencies of Thin Elastic Structures, Part II: Fully Clamped Rectangular Isotropic Plates," J. Sound Vib., vol. 164, no. 2, pp. 295-316, Jun. 1993, doi: 10.1006/jsvi.1993.1215.

[14] L. Azrar, R. Benamar, and R. G. White, "SEMI-ANALYTICAL APPROACH TO THE NON-LINEAR DYNAMIC RESPONSE PROBLEM OF S-S AND C-C 
BEAMS AT LARGE VIBRATION AMPLITUDES PART I: GENERAL THEORY AND APPLICATION TO THE SINGLE MODE APPROACH TO FREE AND FORCED VIBRATION ANALYSIS,” J. Sound Vib., vol. 224, no. 2, pp. 183-207, Jul. 1999, doi: 10.1006/jsvi.1998.1893.

[15] K. El Bikri, R. Benamar, and M. Bennouna, "Geometrically non-linear free vibrations of clamped simply supported rectangular plates. Part I: The effects of large vibration amplitudes on the fundamental mode shape," Comput. Struct., vol. 81, no. 20, pp. 2029-2043, 2003, doi: 10.1016/S0045-7949(03)00152-4.

[16] M. EL KADIRI, R. BENAMAR, and R. G. WHITE, "IMPROVEMENT OF THE SEMI-ANALYTICAL METHOD, FOR DETERMINING THE GEOMETRICALLY NON-LINEAR RESPONSE OF THIN STRAIGHT STRUCTURES. PART I: APPLICATION TO CLAMPED-CLAMPED AND SIMPLY SUPPORTEDCLAMPED BEAMS," J. Sound Vib., vol. 249, no. 2, pp. 263-305, Jan. 2002, doi: 10.1006/jsvi.2001.3808.

[17] E. bekkaye Merrimi, K. El bikri, and R. Benamar, "Geometrically non-linear steady state periodic forced response of a clamped-clamped beam with an edge open crack," Comptes Rendus - Mec., vol. 339, no. 11, pp. 727-742, 2011, doi: 10.1016/j.crme.2011.07.008.

[18] H. Fakhreddine, A. Adri, S. Rifai, and R. Benamar, “A Multimode Approach to Geometrically Non-linear Forced Vibrations of Euler-Bernoulli Multispan Beams," $J$. Vib. Eng. Technol., vol. 8, no. 2, pp. 319-326, 2020, doi: 10.1007/s42417-019-00139-8.

[19] H. Fakhreddine, A. Adri, M. Chajdi, S. Rifai, and R. Benamar, "A multimode approach to geometrically non-linear forced vibration of beams carrying point masses," Diagnostyka, vol. 21, no. 4, pp. 23-33, Nov. 2020, doi: 10.29354/diag/128603.

[20] I. El Hantati et al., "GEOMETRICALLY NONLINEAR FORCED VIBRATIONS OF MULTIPLE-STEPPED EULER-BERNOULLI BEAMS,” pp. 193-204, 2020, doi: 10.47964/1120.9015.19055.

[21] I. El Hantati, A. Adri, H. Fakhreddine, S. Rifai, and R. Benamar, "A Multimode Approach to Geometrically Nonlinear Free and Forced Vibrations of Multistepped Beams," Shock Vib., vol. 2021, no. 4, pp. 1-18, Apr. 2021, doi: 10.1155/2021/6697344.

[22] O. Outassafte, A. Adri, Y. El Khouddar, S. Rifai, and R. Benamar, "Geometrically Non-Linear Free In-Plane Vibration Of Circular Arch Elastically Restrained Against Rotation At The Two Ends," Int. J. Eng. Trends Technol., vol. 69, no. 3, pp. 85-95, Mar. 2021, doi: 10.14445/22315381/IJETT-V69I3P215.

[23] J. R. Banerjee and A. Ananthapuvirajah, "Free flexural vibration of tapered beams," Comput. Struct., vol. 224, p. 106106, 2019, doi: 10.1016/j.compstruc.2019.106106. 